\title{
Article Title: Self, Consciousness and Agency in The Egoist
}

\author{
Submission to: Journal of Victorian Culture
}

Keywords: Meredith, psychology, consciousness, agency, evolution

\begin{abstract}
This article re-reads representations of the self and agency in George Meredith's The Egoist (1879) by drawing new connections between the novel and Victorian psychological theory. Critical discussions of The Egoist and psychological themes have rightly stressed the many ways in which, in Meredith's novel, impersonal forces, biological, physiological and ideological, threaten to obliterate any notion of the self as discrete and autonomous. Yet Meredith maintains a strong ethical investment in individual agency. Comparing metaphors of fluidity, used to describe the self and consciousness in Meredith's text, with similar images taken from the work of G. H. Lewes and James Sully, I argue that Meredith presents the self's plasticity as crucial to its individuation and potential autonomy, even while that same plasticity also underlines the self's vulnerability to social and ideological forces which threaten its independence. Clara's individuality and agency take on distinctive political significance by challenging oppressive gender norms. Yet the vulnerabilities and bewildering complexities of individual subjective life, expressed in Meredith's extravagant extensions of psychological metaphors, mean that any one self's moves towards greater freedom must be fraught with uncertainty. The final part of the essay draws new connections between the psychological imagery that I have been exploring and Meredith's engagement with human evolution. Clara's individuation and capacity for autonomous action give the lie to Willoughby's pseudo-Darwinian schematisation of her identity, yet the relationship between self and evolution remains a serious and complex issue in the novel.
\end{abstract}

$\begin{array}{ll}\text { Author: } & \text { Michael Davis } \\ & \text { Department of Arts and Cultural Industries } \\ \text { University of the West of England } \\ \text { Frenchay Campus } \\ \text { Coldharbour Lane } \\ \text { Bristol } \\ \text { BS161QY } \\ \text { Michael2.Davis@uwe.ac.uk }\end{array}$

\section{Biographical Note}

Michael Davis is a Senior Lecturer in English at UWE, Bristol. He is author of George Eliot and Nineteenth-Century Psychology (2006) and has published essays on Stevenson, Hardy and Wilde. He is currently working on a book-length study of consciousness and agency in Victorian fiction and science, 1870-1900.

Disclosure statement: there is no potential conflict of interest connected with the publication of this essay. 


\section{Self, Consciousness and Agency in The Egoist}

This essay reads George Meredith's The Egoist (1879) in the context of lateVictorian psychological discourse as instanced in the work of two leading scientific psychologists whom Meredith knew personally, George Henry Lewes and James Sully. ${ }^{1}$ Approaching Meredith's novel in these terms, I argue, suggests the value of renewed attention to the concept of agency in his representations of the self. While some earlier studies of Meredith's work have noted the importance of autonomous individual action in his ethical vision, the notion of agency has received far less attention in discussions of his writing in relation to contemporary psychology or physiology. ${ }^{2}$ Instead, critical accounts of Meredith's representations of mind and embodiment have emphasized above all how he radically questions ideas of the self as discrete and active, highlighting his acute sense of the psychological and physiological factors which shape human beings so strongly as to threaten any notion of personal autonomy. ${ }^{3}$ For Clara Middleton, whose attempts to extricate herself from

\footnotetext{
${ }^{1}$ In a letter of September 1879 to Ida L. Benecke, Meredith approves of Benecke's intention of attending lectures on 'Mental Philosophy' and writes that she will be better prepared 'if... [she]... read[s] Lewes and more particularly Bain beforehand - read them'. See The Letters of George Meredith, ed.by C. L. Cline, 3 vols (Oxford: Clarendon Press, 1970), II, 578. Of Bain's and Lewes's work, however, it is Lewes's highly distinctive account of consciousness and individuation that suggests especially close parallels with Meredith's use of metaphor in representing these aspects of the self. In an 1866 letter Meredith refers to Lewes's Biographical History of Philosophy, which contains a discussion of Lewes's theory of mind; Meredith knew Lewes personally as editor of Fortnightly Review when Vittoria was serialized. See Letters, I, 347, 320-1. In an 1883 letter Meredith refers to James Sully as a fellow 'Sunday Tramp', and in later years compliments him on his work on child psychology, the psychology of laughter and the psychology of aesthetics. See Letters, III, 1225, 1469, 1668-69. Later, in his 1902 study An Essay on Laughter, Sully makes a number of brief references to Meredith's fiction as examples of comic literature.

${ }^{2}$ See Gillian Beer, Meredith: A Change of Masks (London: Athlone Press, 1970), pp. 108-09 and Judith Wilt, The Readable People of George Meredith (Princeton: Princeton University Press, 1975), pp. $156-58$.

${ }^{3}$ See especially Nicholas Dames, The Physiology of the Novel: Reading, Neural Science, and the Form of Victorian Fiction (Oxford: Oxford University Press, 2007) and Martha A. Turner, Mechanism and the Novel: Science and the Narrative Process (Cambridge: Cambridge University Press, 1993), both of which I discuss in more detail below. Sean O'Toole places a greater emphasis on agency in 'Meredithian Slips: Embodied Dispositions and Narrative Form in The Egoist', Victorian Literature and Culture 39 (2011), 499-524, which reads the novel in relation to twentieth-century theories of bodily and mental habit, and highlights the thematic importance of characters' resistance to habituated
} 
the prospect of marriage to the monstrously egotistical Willoughby Patterne form the central plot of the novel, the scope for autonomous action is sharply constrained by her gender, young age and lack of financial independence. Yet questions of agency -especially Clara's -- are nonetheless central to the novel's exploration of how a freer and more equal gender politics might be achieved and, in its wake, contribute to Meredith's vision of social progress. These questions are serious concerns in the narrative, notwithstanding Meredith's directing our attention, in his title and in the 'Prelude', to egoism as the main psychological subject-matter.

I make the case for the importance of agency as a viable category in Meredith's ethics, despite the manifold ways in which he shows that it may be limited in individual lives. More particularly, I argue that if we read Meredith's representations of character in the context of Lewes's and Sully's work, the self's very instability, its constant plasticity and dynamic interactions with the world, emerge as the source of its individuality and autonomy of action, as much as they may also, under other circumstances, bear witness to the self's lack of unity and independence. Beyond the immediate scope of my discussion, I contend, too, that the examples of Meredith, Lewes and Sully, who each critically examine the mind's active powers, may point to the need for a stronger focus on representations of agency in our wider understanding of how Victorians constructed the self.

My discussion centres on a set of related metaphors of fluidity - of streams, currents, waves and so-on - which feature in Victorian psychological discourse and which Lewes and Sully use in nuanced ways in their theoretical accounts of minds'

action and thinking. My essay seeks to locate Meredith's treatment of agency in some of its contemporary scientific context. 
individuality and potential for autonomous action. Rather than present an argument about specific scientific influences on Meredith, though such influences must have played a part in his writing, I want instead to trace some of the shared psychological imagery to be found in their accounts and in his novel, to underline at once Meredith's participation in wider psychological debate, and the distinctiveness of his representations of mind. Taking as my focus Clara's struggles towards greater selfknowledge and freedom, I argue that Meredith's novel deploys psychological metaphors specifically to examine the significance of personal agency in genderpolitical struggle. At the same time, his often contorted extension of these images, which point to the labyrinthine vagaries and paradoxes of each self, and to the equally maze-like interactions of self and social sphere, insist on the necessary precariousness of any self's role in contributing to that political change. Liberating action must be highly contingent on the self who acts, with all of the potential for self-deception, or yielding to egoistic drives or social expectation, which such contingency implies. The self's uncertain potential produces a significant difference of emphasis between The Egoist and Meredith's 'An Essay on Comedy' (1877), with which the novel is often read in tandem. The Egoist bears out the 'Essay's contention that genuine civilization makes comedy possible and is in turn shaped by comedy's democratising impetus, and that neither can exist without 'some degree of social equality of the sexes'. ${ }^{4}$ Yet the novel, presenting Clara as a fallible, concretely-realized character amid tangled social circumstance, foregrounds, much more strongly than can the 'Essay', the many psychological and social obstacles facing her attempt to assert her own equality even in the limited sense of choosing her marriage partner. While the 'Essay' insists on the essential parts played by individual self-knowledge and collective 'common sense' in

\footnotetext{
${ }^{4}$ Meredith, 'An Essay on Comedy and the Uses of the Comic Spirit' [1877], in The Egoist, ed. by Robert M. Adams (New York: Norton, 1979), pp. 431-50 (p. 441).
} 
Meredith's vision of social progress, The Egoist renders starkly the difficulty, for individuals, of attaining self-knowledge, and the equal difficulty of defining any such 'common-sense' amid the social and ideological pressures which bear down on the self. $^{5}$ If the overarching comic plot of The Egoist, in charting Clara's attempts to free herself, offers an example of how individual action might contribute to social change, the minute local details of characterisation emphatically demonstrate that any such progress is beset by near-endless vacillations and reversals. One significance of Meredith's notoriously 'difficult' style, exemplified in his use of psychological metaphor, is that it highlights the complex and variable role of individual agency in such change.

As the final part of this essay will show, Meredith's insistence on the subject's inherent fluidity, and potential agency, are also crucial to the novel's engagement with Darwinian discourse. A number of critical discussions of The Egoist have explored its evolutionary themes; the final part of this essay, though, will point to new connections between the novel's evolutionary and psychological discourses, arguing that Meredith's insistence on the subject's inherent fluidity, and potential agency, is an important aspect of his exploration of human identity in its evolutionary context. ${ }^{6}$ Clara's complex and individuated mental dynamics contradict Willoughby's attempts to classify her according to his pet quasi-Darwinian beliefs. Nonetheless, Meredith suggests that if Clara is to achieve a sense of personal agency, and of herself as a discrete mental and physical being, she must attempt to re-connect with her own 'nature' - sexual and psychological, but also evolutionary. Yet this attempt runs up

\footnotetext{
5 'Essay', p. 446.

${ }^{6}$ See Carolyn Williams, 'Natural Selection and Narrative Form in The Egoist', Victorian Studies 27 (1983), 53-79 and Jonathan Smith, “The Cock of Lordly Plume": Sexual Selection and The Egoist', Nineteenth-Century Literature 50 (1995-96), 51-77.
} 
against the fundamental difficulty of describing complex, fluid identity in evolutionary terms, despite the necessary relationship between the two. Her 'natural' self is a crucial point of reference if she is to free herself, but is highly resistant to definition.

\section{Clara's Agency}

The best-known image that Lewes uses to convey his view of the mind's dynamic reality is the 'stream of consciousness.' Both Lewes and Bain deploy the term from the 1850s but, as Rick Rylance has shown, Lewes's later work in the 1870s pursues the metaphor in especially complex and interesting ways to represent the relations between conscious and subconscious experience and identity more widely. ${ }^{7}$ Lewes describes how the emergence or non-emergence of any 'excitation', or neural stimulation, into the fully conscious mind is governed by its strength:

There is thus a stream of Consciousness formed out of the rivulets of excitation, and this stream has its waves and ground-swell: the curves are continuous and blend insensibly; there is no breach or pause. Any increase in the excitability of a particular organ, or neural group, will by raising its level give it a relative prominence, so that for the instant it will constitute the consciousness. And under the incessantly fluctuating waves of special sensation there is the continued ground-swell of systemic [that is, internal] sensation, emotion, or ideal preoccupation, which from time to time emerges into the prominence of consciousness; and this, even when below the waves, is

\footnotetext{
${ }^{7}$ See Rick Rylance, Victorian Psychology and British Culture 1850-1880 (Oxford: Oxford University Press, 2000), p. 307.
} 
silently operating, determining the direction of the general current, and obscurely preparing the impulses which burst forth into action. ${ }^{8}$

Lewes's formulation here illustrates Victorian psychology's willingness to use figurative language inventively. The 'stream' describes the ongoing dynamic between consciousness and subconscious mental events which lie beneath the threshold of the conscious mind but which can readily and rapidly become conscious; it is for this reason that Lewes insists on the distinction between unconscious and subconscious events, since these latter lie much closer to full consciousness. Extending the stream metaphor, Lewes describes the potential of the underlying 'ground-swell' of subconscious energies fundamentally to shape identity by directing the 'general current' and by preparing future 'impulses' and 'action', but he also insists on the fluidity of the interactions between consciousness and the subconscious: these different mental processes 'are continuous and blend insensibly'. Implicit in this passage, too, is Lewes's distinctive theory of the relationship between mind, body and social sphere, and this adds further layers of complexity to his understanding of the self as fluid and dynamic. In common with other physiological psychologists, Lewes insists on the inseparability of the mental and the physical, but for him this applies even to those neurological processes, such as those which guide reflex actions, of which the mind is not conscious. His view contrasts most clearly with Huxley's influential argument that 'the brain is the seat of all consciousness' and that reflex

\footnotetext{
${ }^{8}$ George Henry Lewes, Problems of Life and Mind, 5 vols (London: Trübner, 1874-79), V, 366-67. Subsequent references to this edition are given after quotations in the text. The volumes are numbered thus: First Series: [I] The Foundations of a Creed (1874); [II] The Foundations of a Creed (1875); Second Series: [III] The Physical Basis of Mind (1877); Third Series: [IV] The Study of Psychology: Its Object, Scope and Method (1879); [V] untitled (1879).
} 
actions in the nervous system can best be regarded as purely physical. ${ }^{9}$ Lewes insists that they are not different in kind from what are normally regarded as mental events, since they, too, involve feeling, which Lewes refers to variously as 'Sensibility' and 'sentience' (III, 220), even if the individual is not aware of this. ${ }^{10}$ Though the extract quoted does not deal directly with the question of reflex actions, therefore, it needs to be understood as part of a wider theory which thoroughly integrates the mental and the physical as radically distinct but also inseparable, and which rejects the distinction between any purely physical, or mental, events. Lewes also, moreover, insists on the fundamental role played by the social sphere in shaping minds. 'Social Forms, scientific theories, works of Art, and, above all, Language', he writes, are 'incessantly acting' on each subject (IV, 166), with the result that 'our mental furniture shows the bric à brac of prejudice beside the fashion of the hour; our opinions are made up of shadowy associations, imperfect memories, echoes of other men's voices, mingling with the reactions of our own sensibility' (IV, 167). The mind's fluid variations, then, are inseparable from the life of the body, and are equally inseparable from the complex, perhaps chaotic, relations between the self and the social environment.

A central implication of Lewes's model is the self's individuality. The presence of 'sentience' throughout the body means that, unlike a machine, it is able to respond adaptively to the demands placed on it by lived experience: 'the sensitive mechanism', Lewes writes, 'is not a simple mechanism, and as such constant, but a

\footnotetext{
${ }^{9}$ T. H. Huxley, 'On the Hypothesis that Animals are Automata, and Its History' [1874], in Methods and Results, $5^{\text {th }}$ reprint (London: Macmillan, 1912), pp. 199-250 (p. 205). Roger Smith argues persuasively that Huxley's rhetorical bravado may convey the impression that his views were more stridently held than was really the case. Nonetheless, the difference between Huxley's view and Lewes's is significant. See Roger Smith, Free Will and the Human Sciences in Britain, 1870-1910 (London: Pickering \& Chatto, 2013), p. 24.

${ }^{10}$ Lewes uses 'Sensibility' to describe feeling in its subjective and physical aspects, and 'sentience' to refer to the subjective aspect only of feeling. See III, 220.
} 
variable mechanism, which has a history' (I, 162; original emphasis). That 'history' is, in part, the history of the species, which is passed on to the individual through heredity, but it is also an individual history, composed of that individual's own experiences, which give a distinctive shape to the mind. This distinctiveness means that a subject processes information in necessarily individual ways: the mind is "not a passive recipient of external impressions' but instead exerts influence as 'an active cooperant' (I, 162) in perceiving those impressions.

As this last quotation indicates, the mind's particularity also produces meaningful, if limited, agency. While Huxley argues that 'there is no proof that any state of consciousness is the cause of change in the motion of the matter of the organism' Lewes, though he shares Huxley's view that the self is rooted in the body, nonetheless insists that 'we have, within certain limits, a power of arresting and redirecting the action of our organs or the current of our thoughts' and that 'we can place ourselves under the tutelage of Experience, and so enlarge, and even alter, the primary tendencies, till what was once the immediate reflex of the [nervous] Mechanism becomes abhorrent' (IV, 107). ${ }^{11}$ For Lewes, although all mental phenomena are ultimately caused rather than spontaneously arise, the particularity of each self, and the ability of consciousness to exert causal influence on the self, afford human beings some provisional freedom within the vast chain of cause and effect in which they live.

Meredith's novel shares psychological imagery with Lewes's account but also shares his willingness to grapple with questions of the self's individuality and active

${ }^{11}$ Huxley, 'Automata', p. 244. 
capabilities. These features of Victorian psychological theory and of Meredith's writing, I argue, deserve greater prominence in our understanding of both. Scholars in the field have instead often emphasized ways in which Meredith's novel, and Victorian concepts of the self based in biological science, call into question the very notion of discrete, still less autonomous, selfhood. Nicholas Dames' illuminating study of Victorian fiction and physiological models of reading, for instance, concentrates on ways in which Lewes's work can be seen as part of a wider tendency, among Victorian theories of mind, to see the self as a mechanism and as part of a wider material and cultural system, but pays much less attention to Lewes's equally strong interest in the self's individuation and potential agency. ${ }^{12}$ Reading The Egoist, Dames touches on the possibilities of personal agency by noting that characters' perceptual acts may be 'liberatory', but grounds his account of Meredith's representations of such acts in the concept of 'psychophysics', which understands perception as composed of small, 'isolated bits' of information impacting on the self in a regularized, non-individuated, way. ${ }^{13}$ The emphasis of Dames's discussion is thus on ways in which Meredith presents selves as fragmented, since they are in part made up of these 'isolated bits', and as fundamentally shaped by common psychological processes, and much less on how Meredith also presents characters, even so, as separate wholes. Martha A. Turner offers a related argument, contending that The Egoist shares with Victorian science 'the mechanistic goal of laying bare the rules or principles that dictate events and appearances', and that Meredith's narrative demonstrates 'the essential regularity and comprehensibility of the protagonists' eccentric actions', emphasizing common physiological and psychological events and

\footnotetext{
${ }^{12}$ See Nicholas Dames, The Physiology of the Novel: Reading, Neural Science, and the Form of Victorian Fiction (Oxford University Press, 2007), especially pp. 60, 64.

${ }^{13}$ Dames, pp. 203, 175, 174.
} 
processes above the self's individuation. ${ }^{14}$ In the broader field of scholarship on Victorian representations of the self, William Cohen's influential Embodied reads Victorian texts via late-twentieth-century theories of the body and the senses, and takes a similarly sceptical approach to notions of the self as discrete and autonomous: for Cohen, the Victorian 'embodied subject' 'is not ethereal, transcendent or fixed, in either form or identity, but rather palpable, porous and motile. ${ }^{15}$ These arguments all rightly point to the ways in which Victorian representations of mind radically question notions of an unproblematically unified self. Yet to attend to Meredith's use of metaphors of fluidity is to foreground instead the mind's more active and individuated possibilities, which, for Meredith and for a psychologist such as Lewes, remain just as worthy of attention as the many non-individuated physiological and psychological features shared by all minds. ${ }^{16}$ The central part played by images of fluid mental dynamics in The Egoist's representations of mind confirm that Clara's and other selves may, indeed, be fragmented in the sense that their assumptions about themselves and others are radically challenged in the course of the narrative, and imply that individual selves cannot simply transcend common physiological and psychological factors. But that fluidity also implies non-mechanistic, individual particularity and capacity to act.

Early in the novel, after her misgivings about Willoughby have been heightened by the revelation that it is the impoverished Vernon, and not Willoughby,

\footnotetext{
${ }^{14}$ Turner, p. 117.

${ }^{15}$ William Cohen, Embodied: Victorian Literature and the Senses (University of Minnesota Press, 2009), p. xvi.

${ }^{16}$ A major exception to the relative neglect of the concept of agency is Rylance's seminal study, which includes a superb extended discussion of Lewes's theory of mind, and convincingly addresses concepts of individuation and autonomy. See especially Rylance, pp. 283-85.
} 
who is supporting Crossjay financially, Clara's sense of her changing feelings is experienced as a disconcerting inner flux:

She walked back at a slow pace, and sung to herself above her darker-flowing thoughts, like the reed-warbler on the branch beside the night-stream; a simple song of light-hearted sound, independent of the shifting black and grey of the flood underneath. ${ }^{17}$

Later, as her doubts about the suitability of Willoughby as a husband continue to grow, she pleads a headache and retires to her room, pondering anxiously on the likely reactions to this of Vernon, Horace and Willoughby. She attempts to distract herself with a saccharine vision of life at the Hall as a pastoral idyll, sympathy with which assures her of her 'goodness', even as she in fact contemplates her escape. Her sense of turmoil about her relationship with her fiancé is stronger than ever:

And she had the love of wild flowers, the watchful happiness in the seasons; poets thrilled her, books absorbed. She dwelt strongly on that sincerity of feeling; it gave her root in our earth; she needed it as she pressed a hand on her eyeballs, conscious of acting the invalid, though the reasons she had for languishing under headache were so convincing that her brain refused to disbelieve in it and went some way to produce positive throbs. Otherwise she had no excuse for shutting herself in her room. Vernon Whitford would be sceptical. Headache or none, Colonel De Craye must be thinking strangely of her; she had not shown him any sign of illness. His laughter and his talk sung

\footnotetext{
${ }^{17}$ George Meredith, The Egoist [1879], ed. by George Woodcock (London: Penguin, 1968), p.108. Subsequent references to this edition are given after quotations in the text.
} 
about her and dispersed the fiction; he was the very sea-wind for bracing unstrung nerves. Her ideas reverted to Sir Willoughby, and at once they had no more cohesion than the foam on a torrent-water. (p. 229)

In a description of an internal dynamic similar to that which Lewes outlines, Clara sings to herself 'above her darker-flowing thoughts', an image redolent at once of emotional and bodily energies, and which thus, as in Lewes's account, points to the self's inseparability from physical being. These may or may not form part of her explicit consciousness at this moment, but they are at least partially perceptible as 'thoughts'. This is one of many moments at which Meredith raises the fundamental problem of self-knowledge, a problem which takes on a vividness and urgency as it is explored not in psychological theory but in a specific character's mind and social context, in which gender and class ideologies threaten to obliterate what little selfawareness Clara has. That sense of urgency is heightened in the extension, though it is modest in comparison with others in the novel, of the figure of the stream, to suggest that Clara's efforts to avoid understanding her situation may be as diminutive and fragile as the 'reed-warbler', and that such understanding itself is emotionally threatening. It is heightened, too, in the contrast between the relative bleakness of such imagery and the narrative's predominantly comic tone and the action's idyllic setting. That contrast registers the isolation and limited scope of Clara's view even as the narrator foregrounds her subjective experience and confirms its centrality in the narrative. But, as in Lewes's account of different levels of consciousness which are simultaneously present in the mind, Clara's 'thoughts' are more than simply an intimation that her self-knowledge is incomplete. They constitute other possible shapes and directions, present on the margins of her awareness, which her 
consciousness might take, and which are as much part of herself as the content of her immediate awareness. In Clara's case these possibilities cannot yet fully be acknowledged and thus bring about an act of conscious volition such as Lewes points to in his account. Nonetheless, the fluidity and individuality of her mind - in Lewes's terms a 'variable mechanism' at once physical and mental and able to adapt according to complex lived experience - open up the potential for her freeing herself from her current situation. Her mind retains a degree of particularity, and with this possible autonomy, despite the weight of ideological norms which play on her, and notwithstanding her very limited insight, at this stage, into her own feelings.

In the second extract, the problem of self-knowledge is again to the fore. Clara is seemingly unable to distinguish 'sincerity of feeling' from her rather trite appeals to the beauty of 'wild flowers', 'the seasons' and 'poets', and is 'conscious of acting the invalid' yet also experiencing at least some physical symptoms. Clara's thoughts about Willoughby are almost without 'cohesion' and characterized, instead, by the rapid flow of 'a torrent-water', and this suggests, once again, an unnerving sense of instability in her conscious life and yet also the potential liberation of a transformed consciousness. There is a kind of fluidity about Clara's actually articulable thoughts, too, which means that these seem equally lacking in 'cohesion'. In an example of the impact of 'echoes of other men's voices' to which Lewes refers, Clara's consciousness is momentarily but powerfully invaded by the idea of Horace as 'the very sea-wind for bracing unstrung nerves', a phrase which seems redolent of his own speech, either literally heard or remembered. While his influence over her eventually proves to be considerably weaker than he imagines, an instance such as this nonetheless points to the constant permeability, in Meredith's narrative, of individual consciousness to 
other voices and, potentially, to coercive ideological codes. ${ }^{18}$ As in Lewes's image of the stream of consciousness, explicitly conscious thoughts, such permeability suggests, may be just as readily transformable as the 'flows' of remoter consciousness or the subconscious.

The fluidity of Clara's mind, which produces her particularity, therefore carries a range of implications. In the first extract, it is the source of potentially liberating personal agency but also a reminder of the sheer difficulty of attaining sufficient self-knowledge to realize that agency. The second example again points to the liberatory potential of consciousness as it is re-shaped by the subconscious, but also the vulnerability to oppressive external influence which the self's fluidity carries with it. Both instances illustrate the potential, but also the precariousness, of individual agency, and the sheer difficulty of this problem for Clara as she looks for a way out of her predicament. She thus exemplifies the unpredictable role of individual selves in Meredith's vision, set out in the 'Essay', of social progress driven by a freer gender politics. Her inner unrest hints at the possibility of autonomous action which, eventually, produces narrative closure and gestures towards greater freedom from conventional notions of gender for Meredith's readers, too. Yet the very plasticity of her selfhood leaves her constantly open to her own evasive denials of self-knowledge and to countervailing discourses which threaten to obliterate her efforts at asserting herself, and thus implies that it is impossible to understand her, or any other self, as part of a straightforwardly progressivist narrative.

\footnotetext{
${ }^{18}$ For a detailed and alert reading of Meredith through Bakhtin's concept of heteroglossia, see Neil Roberts, Meredith the Novelist (Basingstoke: Palgrave, 1997).
} 
Elsewhere in the text, descriptions of the self's hidden energies invoke a different kind of flow, that of electricity. As in his use of the stream metaphor, Meredith deploys such electrical images, which are another staple of Victorian psychological writing, to point specifically to the self's potential for liberating personal choice - in Clara's case, to describe the emergence of hitherto non-conscious thoughts which disturb her consciousness and gesture towards the possibility of escape from Willoughby. Vernon Whitford, who is falling in love with Clara, exchanges views with Laetitia Dale, who eventually marries Willoughby, about the couple's relationship; he remarks that 'we never can tell the person quite suited to us; it strikes us in a flash'. To this, Laetitia responds that getting to know another person occurs 'by degrees' (p. 222), and not as a sudden moment of revelation, but Vernon's elaboration of his point implies that both descriptions of the mind's coming to knowledge may be true at the same time: 'Yes, but the accumulation of evidence, or sentience, if you like, is combustible; we don't command the spark; it may be late in falling' (p. 222). Clara, that is, already knows that she does not love Willoughby without being fully conscious that she knows it. A little later in the narrative, when Clara considers more explicitly the 'evidence' against Willoughby, she experiences just such a 'flash' of insight:

She reviewed him. It was all in one flash. It was not much less intentionally favourable than the world's review and that of his friends, but, beginning with the idea of them, she recollected - heard Willoughby's voice pronouncing his opinion of his friends and the world; of Vernon Whitford and Colonel De Craye for example, and of men and women. (p. 251) 
These references to a 'flash' and 'spark' echo the theory of 'unconscious cerebration'. ${ }^{19}$ A leading exponent of the concept, William Carpenter, observes that:

when we have been trying to recollect [...] some name, phrase, occurrence, \&c., $[\ldots]$ it will often occur spontaneously a little while afterwards, suddenly flashing (as it were) into our consciousness, either when we are thinking of something altogether different, or on awaking out of profound sleep. ${ }^{20}$

Carpenter also describes an unconscious mental process as an incomplete "“circuit of thought"" which "may remain for a long time without being "closed.",21 There is no evidence that Meredith read Carpenter, but the concept of unconscious cerebration was referred to by a range of other theorists of mind in the period, including Lewes. Lewes describes his own example: we remember the first letter of a name but not the rest of it, and the unconscious mind strives to piece together the remaining letters until 'suddenly after hours, perhaps days, the name flashes upon the mind' $(\mathrm{V}, 129)$. The 'flash' of realisation to which Vernon refers, similarly, is not an isolated event but instead the product of an 'accumulation' of data already present in the mind, the mobilisation of which enables new understanding. Meredith's elaboration of the metaphors of 'flash' and 'spark', which ignite 'combustible' material in the mind, points to the socially subversive potential of this mobilisation of hidden mental

\footnotetext{
${ }^{19}$ Vanessa Ryan's Thinking Without Thinking in the Victorian Novel (Baltimore: The Johns Hopkins University Press, 2012) convincingly reads Victorian fiction in relation to theories of 'unconscious cerebration' and includes some discussion of The Egoist. Here I deal with some examples not discussed by Ryan, and, as in my earlier comments on other studies in the field, want to put stronger emphasis than does Ryan on the concept of agency.

${ }^{20}$ William Carpenter, The Principles of Mental Physiology with their Applications to the Training and Disciplining of the Mind and the Study of its Morbid Conditions (London: King, 1874), p. 519.

${ }^{21}$ Carpenter, p. 536.
} 
processes. ${ }^{22}$ It is striking that Vernon equates 'evidence' with 'sentience', the latter word, as we have seen, a key term for Lewes in his account of the mind/body relationship; this points once again to Meredith's and Lewes's shared sense of the mind's inseparability from the sensory experience of the body as a whole.

Meredith's uses of the metaphor, however, highlight the uncertainty of result attending subconscious mental processes in the context of individual minds struggling towards self-knowledge and knowledge of others, and towards the liberation these might bring. Laetitia's remark that we 'don't command the spark' emphasizes the seeming chanciness of moments of insight. Clara's 'flash' of realization about Willoughby is immediately complicated by the vaguely-sensed presence of her own, perhaps biased, intention and by the comparison of her 'review' of Willoughby - the term itself connotes an artificial reconstruction of him in her mind as much as a spontaneous perception - with the reviews of other characters, which may confirm or undermine her own. Moreover, Meredith's development of connected metaphors in the same chapter emphasizes that Clara's own 'flash' of awareness offers no automatically reliable guide for action, and thus no clear path to greater freedom. In the lines preceding that moment, we read that 'the fire of a brain burning high and kindling everything lighted up herself against herself', opening her to scrutiny by her 'incandescent reason' (pp. 250, 251). But instead of the socially subversive combustibility which Vernon's phrase suggests, Clara's 'fire' leads her to try to quieten her doubts about Willoughby and to condemn herself as 'volatile' and 'feather-headed' (p. 250). Some lines further on, she is in a state of mind in which 'the brain is rageing [sic] like a pine-torch and the devouring illumination leaves not a

\footnotetext{
${ }^{22}$ For a discussion of this accumulation of data as a version of 'psychophysics', see Dames, pp. 200-03. As I have indicated, my approach seeks to give a more central place than does Dames to the self as individual agent.
} 
spot of our nature covert' (p. 251), but this merely produces further fruitless oscillation between her sense of her own 'weakness' and her 'loathing' for Willoughby. The extended metaphor of 'fire', moreover, is redolent of the psychological figure of the 'flash' but also expresses emotional and bodily distress as the 'flash' does not, and emphasizes that any moment of insight is necessarily embedded in the particular self who has it. Clara's 'flash', then, expresses not just hidden knowledge, as in Lewes's and Carpenter's formulations, but also, crucially, the difficulty for a specific mind of identifying, much less daring to act on, that knowledge, and the punitive emotions that she may experience as a result.

The contrasting possibilities of the mind's active capabilities are in play, too, in specific moments of complex sensory perception which at the same time bring subconscious thoughts into play. Clara feels a 'curiosity' to know the title of the book that Vernon is reading, and is quickly overtaken by a heightened awareness which is unusual both for her and in the narrative itself:

She turned her face to where the load of virginal blossom, whiter than summer-cloud on the sky, showered and drooped and clustered so thick as to claim colour and seem, like higher Alpine snows in noon-sunlight, a flush of white. From deep to deeper heavens of white, her eyes perched and soared. Wonder lived in her. Happiness in the beauty of the tree pressed to supplant it, and was more mortal and narrower. Reflection came, contracting her vision and weighing her to earth. Her reflection was: 'He must be good who loves to lie and sleep beneath the branches of this tree!' She would rather have clung to her first impression. (pp. 154-55) 
This startling instance of aesthetic intensity, in a novel overwhelmingly centred on social comedy, is another point of confluence between Meredith's representations of mind and contemporary psychological theory. In his 1878 essay 'The Undefinable in Art' Sully explores the psychology of aesthetic experience in terms of a fluid combination of conscious and subconscious elements which closely recalls Lewes's 'stream'. When we look at a painting, for example, our enjoyment is composed of perceptions which are distinctly perceived and of others which are less so:

When, for instance, we are deriving an intellectual satisfaction from some particular virgin-shape or gentle face, the many other pleasing elements of the picture contribute each a little rillet of undiscriminated emotion; and these obscure or 'sub-conscious' currents of feeling serve to swell the impression of any single instant, making it full and deep. ${ }^{23}$

The aesthetic effect of any one aspect of the painting, Sully argues, is partly dependent on the many other perceptions of other parts of it, though these perceptions are for the moment outside explicit consciousness. This is a feature of aesthetic experience generally, and points to a fundamental capability that the mind possesses. In any such experience, Sully writes:

We leave many sources of gratification undetected. The whole effect, further, seems to be something more than the sum of the separate elements, even

\footnotetext{
${ }^{23}$ James Sully, 'The Undefinable in Art', The Cornhill Magazine 38 (1878), 559-72 (p. 561).
} 
supposing these to be ascertained [...] In other words, the intermingling of these elements affects us differently from the elements experienced apart. ${ }^{24}$

Sully points here to the limitations of consciousness, but also to its capaciousness and flexibility. He acknowledges that the mind cannot know all of its own operations, yet he also illustrates its ability to perceive a complex whole, such as a painting or landscape, at a single moment rather than as a series of isolated perceptions. For Sully, this exemplifies the mind's role as an agent in its own right, able to combine and make sense of sensory data, rather than just passively receive those data. It is a discrete entity, capable of meaningful action, even while it also ultimately forms part of the wider determining physical universe. Like Lewes, Sully thus places a significantly stronger emphasis on individuality and agency than is the case in Huxley's theory, despite the common basis in physiology which the three share.

Clara's perception of the many small blooms which make up the blossom as a single, whole 'flush of white' manifests, as in Sully's account, her mind's capacity actively to organize, rather than simply to receive, complex sensory information. At the same time, Clara's mental experience proves more complex still - and disconcertingly so - since it is bound up with associated, vague but illicit perceptions of what Vernon is coming to mean to her. Such perceptions offer the possibility of resisting Willoughby's stifling demands which, earlier in the scene, are described as a 'voracious aesthetic gluttony' not only for rigidly-defined feminine 'purity' but also for the consistent and flawless 'performance' of that 'purity' (pp. 151, 150) as a social and ideological signifier. Hinting at possible freedom, however, Clara's aesthetic

\footnotetext{
24 'The Undefinable in Art', p. 562.
} 
experience here also profoundly disturbs her view not just of Vernon and Willoughby but of herself.

The ensuing mental processing of such a dangerous perception highlights once again that the self's plasticity also brings with it vulnerability to coercive social codes and the capacity to evade self-awareness, as much as it offers the prospect of autonomy. Clara's subversive perceptual act is duly rationalized, and hence reduced in its disruptive force, as happiness at the beauty of the tree and then as the relatively uncontroversial, explicit 'reflection' on Vernon. Meredith's constant juxtaposition of competing narrative focalizations, moreover, means that his readers are seldom without a sense of ironic distance from any character's perspective, and there is perhaps a hint of irony even in this moment of inspiration, given the limited scope, and frequent conventionality, of Clara's mental life. Superficially resembling a moment of enlightenment in a Bildungsroman, Clara's experience here offers nothing so momentous: it is a powerful and potentially liberating moment of perception, but it is only a perception, and the description of it is hedged round with a strong sense of her narrow subjectivity. As Anna Maria Jones has argued, Meredith's novel challenges readers to resist the temptation to see Clara's story in terms of a romantic plot with an inevitable movement towards resolution. ${ }^{25}$ Likewise, in the wider context of the novel's vision of possible liberating social change, Meredith takes up a model of mental activity, which recalls Sully's, to highlight the crucial importance of individual, dynamic minds, such as Clara's, as they engage with the world and question conventional gender politics, but also manifests the painful slowness of any such change and the uncertain part that any one self may play in it.

\footnotetext{
${ }^{25}$ See Anna Maria Jones, 'Eugenics by Way of Aesthetics: Sexual Selection, Cultural Consumption, and the Cultivated Reader in The Egoist', Literature Interpretation Theory 16 (2005), 101-28 (pp. 11623).
} 
A similarly complex perceptual act, which again exemplifies the uncertain movement of Clara's mind towards freeing herself, occurs when Clara contemplates the emptied glass of brandy and water which she has shared with Vernon at the station after her abortive attempt to escape. With none of the aesthetic appeal of the blossom, it nonetheless triggers intricate mental processes:

Vernon had asked her whether she was alone. Connecting that inquiry, singular in itself, and singular in his manner of putting it, with the glass of burning liquid, she repeated: 'He must have seen Colonel De Craye!' and she stared at the empty glass, as at something that witnessed to something [...] But all the doors are not open in a young lady's consciousness, quick of nature though she may be: some are locked and keyless, some will not open to the key, some are defended by ghosts inside. She could not have said what the something witnessed to [...] And the smell of the glass was odious; it disgraced her. She had an impulse to pocket the spoon for a memento, to show it to grandchildren for a warning. Even the prelude to the morality to be uttered on the occasion sprang to her lips [...] the conclusion was hazy, like the conception; she had her idea. (p. 335)

The metaphor of the unopened 'doors', Meredith's own, focuses attention on Clara's consciousness as incomplete, characterized by gaps or dead ends which are necessitated by the ideological pressures on her not to know too much about her own desires. The 'ghosts' which defend some of the doors recall the 'shadow of the male Egoist' which, we have read earlier, overawes the 'brains' of young women (p. 153) 
with narrowly prescriptive demands. The extension of the 'doors' metaphor, moreover, turns a mechanistic-sounding figure - of doors open or shut - which might describe a type such as 'a young lady', into something more individual and incalculable - doors to be opened in different ways and offering different kinds of barriers to accessing what is inside. The individuality which this implies, far from offering the possibility of autonomous action, instead underlines the particular, perhaps incalculable, ways in which individual minds may resist or evade awareness which cannot be admitted to consciousness. The incompleteness of Clara's thoughts is then unsatisfactorily replaced by the pat moral object-lesson concerning the spoon which she envisages in an attempt to realign her consciousness with the role that is demanded of her.

Nonetheless, the empty glass does more than uncover gaps in Clara's conscious awareness: it is also the catalyst for 'connecting' events which have just occurred and brings Clara closer to the realisation of her and Vernon's mutual feelings. That Clara becomes aware merely of 'something that witnessed to something' expresses the incompleteness of her thoughts, but it also, in another parallel with Sully, signals the ability of consciousness to embrace new and complex information in a single moment of perception, even if only partially at this stage. The 'conclusion' and 'conception' of the moral tale, similarly, are 'hazy' in a way which points to their artificiality but also registers the more subversive significance, which Clara cannot yet directly acknowledge, of the spoon as an object associated with her relationship with Vernon. Once again, the plasticity of Clara's mind points to the limited scope of her conscious knowledge of her own motives, and the difficulty with 
which she is able to free herself, yet also opens up possibilities of personal agency and liberation and hence points towards potential wider social progress.

\section{Agency and Evolution}

Lewes's and Sully's emphasis on the inseparability of the mind from the body implies that evolution must play a crucial part in the physical and mental development of any self, yet their insistence that the self is individuated and has the potential for meaningful agency means that they firmly resist any reductively evolutionist psychology because this must be inadequate as a model of individual minds' inner dynamics and relations with the world. ${ }^{26}$ Meredith's critique of crude applications of evolutionary theory to human identity suggests further common ground with Lewes and Sully but, as has been pointed out by a number of commentators, is also bound up with his critique of conventional gender politics, since, as Willoughby's evolutionary pronouncements show, evolutionary discourse may be readily appropriated to give quasi-scientific respectability to stiflingly patriarchal demands on Clara. ${ }^{27}$ Nonetheless, questions of evolution's relationship with identity remain crucial since, as John Holmes has argued in his discussion of Meredith's sonnet sequence, Modern Love (1862), Meredith sees the full recognition of women's part in biological evolution, which implies that they are physical, desiring beings, as necessary to a more enlightened understanding of gender which acknowledges the sexuality of both

\footnotetext{
${ }^{26}$ Sully, for instance, writes that, though evolution has clearly played a crucial part in the formation of each mind, 'yet, it must be admitted even by the evolutionist, that at least a considerable number of mental phenomena are susceptible of explanation by means of processes observable within the individual life.' See 'The Relation of the Evolution Hypothesis to Human Psychology', in Sully, Sensation and Intuition: Studies in Psychology and Aesthetics (London: King, 1874), p. 8. As I will go on to show, Lewes takes a similarly cautious attitude towards using evolutionary models in our understanding of human identity.

${ }^{27}$ See Williams and Jonathan Smith. My discussion adds to these studies by focusing more concerted attention on Meredith's sense of the limitations, as well as necessity, of seeking to understand human identity in evolutionary terms.
} 
sexes. ${ }^{28}$ Clara's attempts to locate her identity in relation to evolution, in the sense of acknowledging and making her own sexual choice, are therefore crucial to her agency and status as a discrete individual. At the same time, her example shows, once again, that the self's fluidity and individuation have varied and perhaps contradictory implications: they may enable individual choice but may also bring to the fore the precariousness of individual agency amid competing social, ideological and psychological pressures.

Vernon, sure of the inevitability of Clara's falling in love with Horace, tells Laetitia that 'our modern word for it is Nature. Science condescends to speak of natural selection' (p. 369). Yet a few moments before this he describes Clara's dilemma as 'a dispute between a conventional idea of obligation and an injury to her nature...It's one of the few cases in which nature may be consulted like an oracle' ( $p$. 368). This latter formulation suggests that there is, indeed, a 'nature' which Clara needs to connect with if she is to resist Willoughby's entrapment and assert her own agency, and that that 'nature' must, in part, be biological. But Vernon's remark also exemplifies the contrasts, and potential slippage, of meaning between 'nature' as impersonal biological process, as bodily self, as essential character and, alternatively, as complex, developing individuality; no longer capitalised and reified, the term now takes on an uncertain meaning. Laetitia's reply, 'Is she so sure of her nature?' (p. 368), makes this point more forcefully.

Shortly afterwards the difficulty of defining Clara's 'nature', given her complex mental dynamics, becomes even more apparent:

\footnotetext{
${ }^{28}$ See John Holmes, 'Darwinism, Feminism, and the Sonnet Sequence: Meredith's Modern Love', Victorian Poetry 48.4 (2010), 523-38 (pp. 533-34).
} 
She had but one answer: 'Anything but marry him!' It threw her on her nature, our last and headlong advocate, who is quick as the flood to hurry us from the heights to our level, and lower, if there be accidental gaps in the channel. For say we have been guilty of misconduct: can we redeem it by violating that which we are and live by? The question sinks us back to the luxuriousness of a sunny relinquishment of effort in the direction against tide. Our nature becomes ingenious in devices, penetrative of the enemy, confidently citing its cause for being frankly elfish or worse. (pp. 395-96)

Her 'nature', psychological but also evolutionary, cries against the prospect of life with Willoughby and pushes Clara towards recognising her own desires, a recognition which might free her from him and from the patriarchal norms which he embodies. Yet that 'nature' proves to be definable rather in opposition to Willoughby's sexual and ideological pressure than in its own right. Far from constituting any one essence, the extended comparison with the 'flood' implies, the self's inward energies may take unpredictable directions, a fact which makes impossible the definition of the self in terms of any one 'level', whether moral or otherwise psychological. As ever, the self has the ability to become 'ingenious in devices' of self-justification and it must also exist in ongoing interaction with the social and ideological environment, and this emphasizes the variety of shapes which it may take in its life. Given that disconcerting variety, Clara's attempt to listen to her own 'nature' is urgent, for her and for Meredith's vision of a more equal gender politics, but also full of potential confusion. Her fluid self may be as likely simply to confirm her own self-indulgent egoism as it is to free her. That same potential for confusion is implied, elsewhere in the narrative, in Clara's 'hundred-voiced instinct of dislike within her' (p. 493) 
towards Willoughby. This may, indeed, be an 'instinct' which questions his evolutionary fitness as a mate, but it also arises, and is felt in the context of, a complex, 'hundred-voiced' self whose operations cannot be described in terms of a unitary instinct. That complexity subverts Willoughby's crude evolutionism, which sees 'woman' as 'having no passion of her own, but simply an instinct driving her to attach herself to whatsoever is most largely admired, most shining' (p. 362). At the same time, the concept of 'instinct' points to the inseparability of mind and biology. Yet the 'hundred-voiced' self also implies the ever-present difficulty of disentangling instinct from the maze of more or less acknowledged motives, and interpersonal and ideological influences, which converge in that self, and which may produce what is apparently a clear instinctual prompting to action. Given such complication, for Clara even to identify what it is that she wants may be far from straightforward.

The complex significance of the evolutionary in Clara's selfhood is also in evidence much earlier in the novel in a moment which suggests another instance of Meredith's creative use of psychological language in his exploration of personal agency and gender politics. Willoughby's desire for complete mastery over Clara is disturbed by hints that her mental and bodily life may evade his control:

She certainly had at times the look of the nymph that has gazed too long on the faun, and has unwittingly copied his lurking lip and long sliding eye. Her play with young Crossjay resembled a return of the lady to the cat; she flung herself into it as if her real vitality had been in suspense till she saw the boy. Sir Willoughby by no means disapproved of a physical liveliness that promised 
him health in his mate; but he began to feel in their conversations that she did not sufficiently think of making herself a nest for him. (pp. 127-28)

Willoughby's suspicion here seems not to be focused on the possibility of actual sexual transgression by Clara. The comparison with the nymph and faun has grown out of Willoughby's vague sense, in the previous paragraph, of her 'innocent roguery, wildwood roguery' (p. 127), and the perception merely that she has 'unwittingly copied' the facial expressions of the faun, and thus that her outward demeanour has momentarily failed to conform to the self-effacing modesty of his ideal wife, is enough to disconcert him. He is also disturbed, however, by Clara's 'real vitality', which appears to be reserved for Crossjay and which thus seems to indicate aspects of her emotional life which lie outside Willoughby's knowledge and control, despite his recourse to the (for him) reassuring evolutionist paradigm which sees her 'physical liveliness' as indicative simply of 'health in his mate'. The subversive potential of Clara's 'vitality' is highlighted if we compare it with Lewes's use of the same concept as another important term in his theory of mind. Discussing the distinction between organisms and machines, which I touched on earlier, he writes:

One cardinal difference is that the combination of the parts is in the machine a fixed, in the organism a fluctuating adjustment; and this fluctuation is due to certain vital processes subjectively known as sensitive guidance. Hence machines have fixed and calculated mechanisms; whereas organisms are variable and to a great extent incalculable mechanisms. (III, 365) 
For Lewes it is the presence of 'sensitive guidance' or sentience, in organisms which means that they have a potential to develop not possessed by machines; here, his discussion refers to organic life in general, but, as we saw earlier, the same insistence on fluid adaptability by means of sentience informs Lewes's theory of the human mind specifically. This distinctive feature of organic life implies that any process taking place in a living organism, even if that process seems simple, needs to be understood as 'not physical' as would be the case in a process carried out by a machine, but instead 'vital' (III, 366) since it takes place in a sentient and changing being. Vitality, therefore, entails an important element of individuality in the organism, and Lewes stresses this point in his stance towards Darwin's theories. Applauding 'that luminous hypothesis by which Mr. Darwin has revolutionised Zoology' (III, 115) Lewes also, however, warns against reifying the abstract concept of species, or 'Type', as if it had a reality in itself. Instead, all individual organisms are, indeed, individual, and species offer only an approximate guide to the size, shape and relationship to the environment which each individual possesses. This is because each organism's life is not the product of a rigidly defined blueprint, as the abstract notion of 'Type' might seem to imply, but rather develops through the ongoing interactions not just between heredity and environment but between these and the conditions within each organism taken as an individual. The organism, he writes, 'is this particular organism, differing from others, because of the particular conditions [in the environment and in the organism itself] which have co-operated' (III, 116). In Lewes's view, the importance of attending to the particularity of the organism constitutes a significant caveat to Darwin's primary focus on common conditions of heredity and environment. 
Meredith's reference to Clara's 'vitality' implies an analogous, and much more ideologically challenging, qualification to Willoughby's evolutionist assumptions: it is necessarily bodily and may, indeed, indicate her health and potential suitability as a 'mate' likely to bear offspring successfully, yet it is also discrete and specific to Clara. It denies Willoughby's attempts to superimpose on it his crude evolutionary beliefs, which try to subsume her subjectivity into the familial and social structure of Patterne Hall, and instead suggests that Clara is a biological organism who is also, however, individuated and capable of autonomous action. Clara's 'vitality' contrasts sharply with the 'vital essence' (p. 119) which, in the previous chapter, Laetitia detects in Willoughby; that phrase serves precisely to confirm his place in the existing social structure because it celebrates his physical being as the embodiment of his patriarchal, economic and hereditary power. The inseparability of Willoughby's 'vital' existence from his overwhelming need for control and prestige is confirmed later in the narrative when we read that 'the world's view of him', especially when he is threatened with the humiliation of being jilted a second time, is 'partly his vital breath, his view of himself' (p. 449), the moderating 'partly' giving way to an extreme image in which his very bodily existence seems conflated with his perception of his own social standing. Clara's vitality, by contrast, points to the separateness of her subjectivity, and also hints at her sexuality, both of which undermine Willoughby's evolutionary theorising and his wider attempts to control her. At the same time, however, Clara's individuality, which resists definition according to Willoughby's biological scheme, can, precisely because it is individual, offer no certain source of liberating action and hence of possible wider social progress. The potential subversiveness of her vitality is real enough, but that vitality is 
just one aspect of Clara's wider selfhood, which remains conflicted and open to manifold psychological and ideological influences.

Meredith, I have been arguing, is at once highly sceptical about the powers of human agency and yet also insistent on its importance in freer gender politics and social progress. His elaborations of psychological metaphors describe a complexity in mental dynamics which at times promises individual independence in the face of ideological pressures dramatized in the text, and at others suggests the self's vulnerability to, and complicity with, those pressures. In the novel's engagement with questions of human evolution, the dynamic self's contrasting possibilities offer, on the one hand, a source of resistance to reductively-used Darwinian discourse and an impetus to redefine the self's relationship with biology and, on the other, confusion, borne of the self's very complexity, about what that relationship may be. Meredith's idiosyncratic rendering of mental dynamics in particular, concretely-realized characters, and in the context of his critique of gender norms, is an example of what Roger Smith has convincingly argued is the distinctive contribution of the Victorian novel to the development of complex models of the self in the period. ${ }^{29}$ But the shared metaphors in Meredith's novel and Lewes's and Sully's work also underline the importance of the concept of agency to Victorian psychological discourse more generally, and exemplify the saliency of that discourse, and of debates about agency, to questions about human beings' relationship with evolution. It might be speculated that the continued influence of twentieth-century critical theory, with its radical questioning of the notion of the discrete individual and concomitant focus on social and discursive systems instead, has meant that the concept of agency has been less

\footnotetext{
${ }^{29}$ See Roger Smith, p. 155.
} 
central than it deserves to be in scholarly work on the self in Victorian culture. If so, a renewed sense of the Victorians' complex engagement with notions of the self as active being, an engagement limited neither by the classic humanist notion of the unified self nor by the throughgoing scepticism, of later critical theory, about human agency, may be one way forward now. 